\title{
ENTRE EL «SUEÑO ZAPATISTA»Y EL «SUEÑO AMERICANO»: LA MIGRACIÓN A ESTADOS UNIDOS VISTA DESDE LAS COMUNIDADES ZAPATISTAS
}

ALEJANDRA AQUINO MORESCHI*

RESUMEN: La migración de chiapanecos a Estados Unidos es un fenómeno reciente pero que ha cobrado gran fuerza y está transformando las dinámicas locales en casi todo el estado, incluso en los municipios zapatistas, donde las salidas al Norte se habían retrazado ante la opción de la lucha y el diálogo. Hoy la migración se ha convertido en un proyecto que no sólo le disputa sus bases al movimiento, sino que también compite con éste como nuevo productor de subjetividades. A partir de la reconstrucción del fenómeno migratorio en una comunidad zapatista de la Selva Lacandona, me propongo mostrar cómo ésta provoca un conflicto comunitario en el que se oponen dos tipos de subjetividades y en el que los diferentes actores se disputan la definición de sentido de la acción migratoria y la forma de gestionarla. Se mostrará también, cómo en medio de grandes tensiones, las comunidades zapatistas pasan de una etapa de repliegue defensivo ante el fenómeno a una de apertura.

PALABRAS CLAVES: migración internacional, gestión de la migración, zapatismo, Chiapas, conflicto

ABSTRACT: Chiapaneco migration to the United States is a recent and increasingly large phenomenon that is transforming local dynamics across the state, even in Zapatista municipalities where emigration had been delayed during times of struggle and perceived dialogue opportunities. Today, migration is wearing down the movement and creating a new set of subjectivities. This paper reconstructs the migration phenomenon in a Zapatista community of the Lacandon Jungle and, in doing so, intends to show the ways in which it leads to a communal conflict involving two different types of subjectivities as different actors argue over the meaning of migration and how to manage it. I will also show how, in the midst of great tension, Zapatista communities go through a stage of defensive retreat when faced by this new process.

KEYWORDs: international migration, migration management, Zapatismo, Chiapas, conflict.

\footnotetext{
* École des Hautes Études en Sciences Sociales (eHess), Paris, doctorante en sociología adscrita al
} Centre d'Analyse et d'Intervention Sociologiques (CADIS), aa_moreschi@yahoo.com 

edad de 16 años. Fue el primer joven de su pueblo en emprender el camino al Norte. Él es originario de una pequeña comunidad de la Selva Lacandona a la que en estas páginas llamaré María Trinidad. Desde que era pequeño, su familia participó en el Ejército Zapatista de Liberación Nacional (EZLN). Eugenio creció en medio de la lucha, entre convenciones nacionales, encuentros intercontinentales, diálogos de paz, consultas ciudadanas, marchas, etc. Cuando el padre de Eugenio anunció la partida de su hijo frente a la Asamblea Comunitaria, la noticia causó conmoción al interior del pueblo; sin embargo, no tomó a nadie por sorpresa. Desde hacía tiempo, la idea de emigrar giraba en la cabeza de algunos jóvenes del pueblo, aunque todavía ninguno se atreviera a admitirlo en el espacio público. Para ese momento muchos jóvenes de las comunidades no-zapatistas de la región se encontraban ya en Estados Unidos y sus historias circulaban por toda la cañada, despertando la curiosidad de las bases rebeldes y conformando un imaginario colectivo en torno a la vida al otro lado de la frontera.

Chiapas se ha consolidado como uno de los principales estados expulsores de migrantes; según información de la Conapo con base en datos de la «Encuesta sobre Migración en la Frontera Norte de México» (EMIF), en 2008 Chiapas fue el estado que más migrantes envió a Estados Unidos (14\%), incluso por encima de Guanajuato (8.6\%) y Oaxaca (7.2\%), estados con una antigua tradición migratoria. ${ }^{1}$ Aunque algunas fuentes registran desde 1925 la presencia de chiapanecos en Estados Unidos (Departamento de Trabajo de Estados Unidos, en Jáuregui y Ávila, 2007: 21), hasta finales de la década de los ochenta estos desplazamientos fueron tan reducidos que pasaron prácticamente desapercibidos y no tuvieron consecuencias significativas para el estado. ${ }^{2}$ Fue hasta los años noventa cuando la migración chiapaneca se volvió visible, y fue hasta la década de 2000 cuando el fenómeno se generalizó por todo el estado y se volvió masivo (Jáuregui y Ávila, 2007; Villafuerte y García, 2006; Pickard, 2006).

Los municipios zapatistas no han quedado al margen de la dinámica migratoria del estado; difícilmente podrían hacerlo ya que, por todos lados, la tendencia

\footnotetext{
1 Véase el documento basado en la Encuesta sobre Migración en la Frontera Norte de México (EMIF): "Migrantes procedentes del sur con destino a Estados Unidos, según características del lugar de origen en México», 2008. Disponible en: http://www.conapo.gob.mx/index.php?option=com_content \&view $=$ article\&id $=388 \&$ Itemid $=379$

2 Durand y Massey (2003: 89) atribuyen este «retraso» a dos factores: un sistema de enganche de trabajadores que operó exclusivamente al interior del estado (migración interna) y su mínima participación en el Programa Bracero (1942-64). Otro factor que retrasó el comienzo de la migración fue el alto índice de pobreza y marginación que existe en el estado, pues como sostienen Durand y Massey (2003: 90) la migración no suele estar asociada con la pobreza extrema.
} 
es que el fenómeno se acelere e intensifique. Además, aunque los municipios zapatistas funcionan como entidades territoriales autónomas, éstas no se encuentran aisladas del resto de la sociedad; por el contrario, en sus territorios de influencia existe una interacción permanente entre zapatistas y no-zapatistas, quienes en muchos casos conviven dentro de las mismas comunidades.

En la región en la que realicé mi investigación, las bases zapatistas fueron las últimas en emprender el camino al Norte. Durante varios años, el zapatismo logró contener la migración de cientos de jóvenes que mantenían la esperanza de que sus reivindicaciones se podrían resolver en el mediano plazo por medio del diálogo con las autoridades gubernamentales y la sociedad. Cuando el gobierno foxista, con el apoyo de los tres principales partidos (Partido Revolucionario Institucional, Partido Acción Nación y Partido de la Revolución Democrática), aprobó una ley indígena que traicionó lo pactado en el Diálogo de San Andrés (Hernández, Sarela y Sierra, 2004), quedó claro que el diálogo no sería la salida y que la victoria estaría todavía lejos. Es en este momento cuando la migración se convierte en una nueva alternativa para muchos jóvenes zapatistas.

La migración chiapaneca a Estados Unidos representa un enorme desafío para el movimiento zapatista, no sólo porque implica la pérdida de sus bases más jóvenes, aquellas que parecían el relevo generacional «natural» del movimiento, sino también porque introduce nuevos valores, sentidos y horizontes, y de esta forma le disputa al zapatismo la hegemonía como proyecto político y de vida en la región. Los migrantes, aun sin darse cuenta, difunden un nuevo estilo de vida que tiene efectos concretos en los pueblos en resistencia.

El siguiente artículo resume algunos de los resultados de mi tesis doctoral; su objetivo central es contribuir a la comprensión de lo que está sucediendo al interior de los pueblos zapatistas que se enfrentan por primera vez al fenómeno migratorio. La reconstrucción del proceso migratorio en María Trinidad me permitirá mostrar el tipo de conflictos, debates, negociaciones y acuerdos que están teniendo lugar en estos pueblos, así como los múltiples sentidos que los diferentes actores de las comunidades le dan a la migración. ${ }^{3}$

\section{¿QUIÉNES SE VAN?}

Igual que en el resto del estado, en las comunidades zapatistas emigran sobre todo hombres jóvenes de entre 15 y 35 años. Con fines analíticos voy a distinguir dos diferentes perfiles de migrantes: los «zapatistas de cuna» o de «segunda generación» y los zapatistas de la "generación 1.5». Es importante hacer esta distinción, ya que la experiencia dentro del movimiento es diferente en cada caso, así como

3 Toda la información aquí presentada proviene del trabajo de campo que realicé entre 2005 y 2007, en Chiapas, California y, particularmente, Mississippi. La estrategia metodológica utilizada fue la combinación de la observación directa y la realización de entrevistas a profundidad. 
el lugar que la militancia ha ocupado en sus vidas y el tipo de compromiso militante que establecieron con el movimiento. Cuando hablo de "generación» no lo hago en un sentido biológico, reducido a un criterio de edad, me refiero más bien al tipo de experiencia militante que les tocó vivir.

La generación de los «zapatistas de cuna» está formada por todas aquellas personas que vivieron su niñez y adolescencia en la era post levantamiento (después del primero de enero de 1994). A esta generación ya no le tocó conocer cómo fue la vida en la selva antes de la rebelión y el establecimiento de los municipios autónomos. Desde que eran pequeños, la región estuvo en manos del ezLn, por lo que nunca tuvieron que trabajar bajo las órdenes de un patrón, no trataron jamás con los funcionarios gubernamentales, ni tampoco asistieron a las escuelas del gobierno. Todos ellos estudiaron en las escuelas autónomas zapatistas y se atendieron en sus clínicas. Es una generación que nace «dentro» del zapatismo, de tal forma que su participación en el movimiento, al menos en un principio, no es producto de una decisión personal, es una adscripción heredada de sus padres y reforzada por un entorno familiar y comunitario en el que todos son zapatistas. Desde muy pequeños, todos estos jóvenes comenzaron a involucrarse en distintas actividades del movimiento; por ejemplo: acompañaban a sus padres a las reuniones de la organización y asistían a las festividades o los eventos convocados por el EZLn. La lucha impregna todos los resquicios de su vida cotidiana, incluso actividades antes familiares como la siembra de maíz, después del levantamiento en algunas comunidades se colectivizan con la idea de poder "resistir mejor» en la larga lucha (veáse Aquino y Maldonado, 1998).

Aunque esta generación crece en un medio muy politizado, no recibe una formación política del mismo tipo que la generación anterior. Es una etapa en la que todos los esfuerzos del movimiento se orientan a la negociación con el gobierno federal y el cumplimiento de los acuerdos de San Andrés, la construcción de lazos con la «sociedad civil» nacional e internacional y la formación de sus municipios autónomos. En cambio, la formación de nuevos cuadros rebeldes queda un poco de lado.

La «generación 1.5» es aquella que se encuentra entre los fundadores del movimiento - primera generación-y los zapatistas de «segunda generación». Se trata, en general, de jóvenes que nacieron entre 1970 y 1980, y que en 1994 tenían entre 14 y 24 años. Es una generación que todavía llegó a conocer lo que fue la vida en la región antes del levantamiento: estudiaron en las escuelas de la Secretaría de Educación Pública (SEP), conocieron a los funcionarios gubernamentales, fueron testigos de las dificultades que enfrentaron sus padres para regularizar sus tierras y comercializar su café, incluso llegaron a participar en las organizaciones campesinas. Estos jóvenes todavía crecieron con la esperanza de poder beneficiarse del reparto agrario y fueron la generación más afectada con las reformas al Artículo 27 pues ya no pudieron solicitar tierras. 
Dentro de esta generación encontramos tanto a jóvenes que se integraron al movimiento en la época de la clandestinidad, como a los que ingresaron un poco después del levantamiento. Casi todos participaron activamente en los Grupos Juveniles Zapatistas. Para ellos, el ezLn fue como una «escuela» en la que se politizaron o, como ellos dicen, en la que se les «abrieron los ojos». En todos estos casos, el ingreso al zapatismo fue producto de una decisión personal -tomada en un contexto favorable a este tipo de decisión-y estuvo motivada por diversas expectativas como mejorar su situación económica, obtener tierras, obtener reconocimiento, transformar su entorno político, etc.

Para todos estos jóvenes la militancia en el zapatismo ocupó durante varios años un lugar central en su vida y fue una fuente de sentido central de su existencia. Es una generación que creyó en el «sueño zapatista», que proyectaron su futuro en el movimiento y estuvieron convencidos de que su militancia en el ezLN era la mejor vía para conseguir lo que querían.

\section{EL CONFLICTO COMUNITARIO FRENTE A LA MIGRACIÓN}

Los primeros en irse al Norte fueron los zapatistas de cuna. Cuando el padre de Eugenio planteó en la Asamblea que iba a mandar a su hijo a Estados Unidos el argumento que dio fue económico: «necesito dinero para reconstruir mi casa, para levantar todo lo que el ejército destruyó cuando entró al pueblo». La noticia causó revuelo en la comunidad. Las bases zapatistas no sabían cómo reaccionar, ni que postura tomar frente a esta situación. La migración trasnacional era algo inédito en el pueblo, no formaba parte de sus repertorios de acción, no estaba incorporada como una estrategia económica, ni como una forma de vida. Hasta ese momento, el único tipo de emigración que conocían tenía como destino Cancún o Ciudad del Carmen, duraba periodos muy cortos -tres a cuatro meses-y se desarrollaba con el acuerdo previo de la comunidad. Además, en ese momento la migración estaba asociada con los jóvenes no-zapatistas pues eran los únicos que se iban al Norte. Las tensiones internas crecieron, el conflicto se hizo cada más grande y al final los que decidieron emigrar tuvieron que dejar el movimiento, en ese momento no cabía la idea de emigrar y seguir siendo zapatista. La militancia en el zapatismo se veía como una práctica, una acción cotidiana, un modo de vida y no sólo un sentimiento, una filiación o una ideología que pudiera mantenerse sin la acción de todos los días. Además, como explica una base zapatista de la primera generación:

Teníamos miedo que todos los jóvenes se fueran porque habíamos visto (en otros pueblos) que la migración es como el vicio, cuando uno la prueba ya no la puede dejar. Entonces nos cerramos, nos pusimos duros, dijimos «nadie sale», pensamos que así íbamos a poder detenerla, pero no, fue peor, parece que a los muchachos más ganas les dieron de irse (Pablo, Chiapas, 2006). 
El conflicto por la migración se expresó en gran medida como un conflicto por darle sentido a la acción migratoria. En ese momento se enfrentaron dos posiciones que parecían irreductibles: las bases que veían en la migración de sus compañeros una rendición, un abandono de la lucha y un peligro para la comunidad; y aquellas para quienes la migración no significaba una rendición, sino una forma legítima de obtener recursos económicos, una liberación, una aventura, una forma de rehacer su vida e incluso una moda.

El conflicto también expresa la fricción que existe entre dos distintas lógicas que conviven al interior de algunos pueblos zapatistas: la lógica militante y la lógica migrante. En la primera, la acción colectiva por el bien común ocupa un lugar central, y la comunidad y la organización colectiva tienen el más alto valor. En la lógica del migrante, el proyecto de la acción colectiva es desplazado por un proyecto personal o familiar, por una búsqueda propia; aunque desde esta perspectiva la comunidad sigue siendo un referente importante, ya no es el centro, ni la principal fuente de sentido para los actores.

El conflicto finalmente nos habla también de la necesidad de renovar un modelo de militancia que funcionó muy bien durante casi dos décadas, pero que ante el fenómeno de la migración masiva resultó estrecho. Tal como han logrado hacer los zapatistas en otras regiones, se necesita flexibilizar las formas de participación en el movimiento para que los jóvenes de segunda y tercera generación que aspiran tanto a emigrar, como a seguir siendo zapatistas, puedan tener un espacio para hacerlo.

Pese a las múltiples tensiones que provocaron las primeras migraciones hacia Estados Unidos, éstas permitieron hacer visible un problema del que no se hablaba pero que ya era presente en todo el estado y abrieron un espacio para la deliberación al interior de las comunidades. Como sostiene Alberto Melucci (1999), el conflicto deja que salga a la luz pública lo que el sistema no dice por sí mismo; es decir, indica al grupo que hay un problema que concierne a todos sus miembros, y en torno al cual están surgiendo nuevos códigos, nuevos significados y nuevas formas de poder. En este caso, permitió abrir un espacio para negociar bajo qué modalidades se deben dar las salidas, así como los sentidos que se le otorgan.

Cabe mencionar que no en todas las comunidades la migración de los jóvenes se traduce en un conflicto comunitario. Si en María Trinidad sucedió de esta manera fue, en gran medida, porque la migración coincidió con la salida de algunas familias del ezLn. ${ }^{4}$ En ese momento todos tenían la duda de si las bases rebeldes dejaban el movimiento porque querían emigrar o si emigraban porque querían dejar el movimiento, de ahí que migración y defección se equipararan y fueran tratadas como un mismo proceso.

\footnotetext{
${ }^{4}$ Hasta ese momento María Trinidad había sido una comunidad unida donde, como ellos mismos dicen: «Hasta las gallinas son zapatistas». Fue un pueblo que durante más de diez años logró escapar de las divisiones que el gobierno intentaba provocar con la presencia del ejército y el ofrecimiento de diferentes programas sociales.
} 


\section{LA MIGRACIÓN COMO RENDICIÓN, ABANDONO Y PELIGRO}

Como ya se dijo, el conflicto migratorio es, en gran medida, una disputa de sentidos y en toda la primera etapa predominó una interpretación negativa. Las bases zapatistas vieron la salida de sus compañeros como una «rendición» en el sentido de dejarse vencer por el desánimo y el cansancio provocados por la guerra de baja intensidad. Vieron también en ésta un peligro para la comunidad y un triple abandono; pues quienes emigran dejan sus cargos y obligaciones comunitarias, dejan un proyecto emprendido colectivamente en el que todos han invertido mucho esfuerzo y dejan también a su familia.

En María Trinidad la salida de los jóvenes se vive con dolor ya que, para cualquier comunidad indígena, la pérdida de su población masculina en edad productiva constituye una grave amenaza para su reproducción, lo que Mutersbaugh (2002) llama la «muerte cívica». Este sector de la población no sólo se encarga de proveer el alimento y los demás recursos para el sustento de las familias, también debe aportar los servicios comunitarios y los trabajos colectivos que se necesitan para el buen funcionamiento de la comunidad. En el caso zapatista, la amenaza es doble, ya que la salida de los jóvenes no sólo pone en peligro la reproducción comunitaria, sino también el funcionamiento de los municipios autónomos y los diferentes proyectos que se han impulsado.

Como ha sucedido en otros pueblos de México, en María Trinidad uno de los primeros efectos de la migración es la falta de ciudadanos para cumplir con los «servicios» y trabajos colectivos que se necesitan para el buen funcionamiento de la comunidad y, en este caso, también del movimiento. Lo anterior se refleja en el aumento del trabajo para los que se quedan y, por lo tanto, el aumento de las tensiones. Como explica un joven zapatista promotor de educación:

Como mi compañía se corrió, yo ahora no puedo hacer bien mi trabajo, tengo que ocuparme de su grupo, me quedó todo el trabajo a mí. ¿̇De qué sirvió tanto curso que tomamos para prepararnos, tanto esfuerzo de la comunidad de apoyarnos si de por sí se iba a ir? Además, como otros «compitas» también se corrieron, yo y el otro promotor que quedó vamos a tener que ir a ayudar al campo porque no se dan abasto los hombres. Los niños se van a quedar sin clases, no es justo, yo también tengo necesidad, tengo mi bebé y no por eso me voy (Elmer, Chiapas, 2006).

Otro efecto de la migración que se percibe como negativo es que con el dinero de las remesas, algunas familias han intentado emprender «negocios» personales que entran en competencia con los proyectos colectivos de las bases zapatistas y atentan con el ideal de construir comunidades igualitarias, promovido tanto por el movimiento como por la iglesia católica.

Particularmente entre las mujeres, la migración es vista como una amenaza para sus familias, ya que existen varios casos de abandono de parte del esposo 
migrante. Lo que desde la lógica comunitaria no es un problema privado, sino público, ya que la comunidad es responsable de todos los miembros del grupo y es la que tiene que solucionar el problema de la familia que se queda sola.

Cabe mencionar que la desconfianza que provocó la migración es en gran parte resultado de lo que se ha observado en otros pueblos de la región, cuya migración ha funcionado como una "profecía» que anuncia lo que dentro de poco podría pasar en las comunidades rebeldes: abandono de los pueblos, debilitamiento de la organización comunitaria, introducción de nuevos valores y estilos de vida contrapuestos a los valores comunitarios, desintegración familiar, abandono de la agricultura, alcoholismo, drogadicción, delincuencia, y enriquecimiento personal, entre otros.

\section{LA MIGRACIÓN COMO NECESIDAD ECONÓMICA}

Frente a la imagen de la migración como abandono, rendición o peligro, los migrantes han producido una imagen positiva, mediante la cual justifican su partida: la migración como necesidad económica; es decir, como un medio legítimo para "ganarse la vida», «salir adelante», «avanzar», «mejorar», «levantarse un poco».

En este caso los migrantes tratan de mostrar que la migración representa menos un deseo personal, que una «obligación» que les impone su difícil situación económica y su responsabilidad frente a su familia. Este tipo de argumento fue utilizado particularmente por los zapatistas de la generación 1.5, ya que son quienes tienen familia dependiente, como explica uno de ellos:

Nosotros decidimos emigrar por la necesidad de mejorar a nuestras familias en la pobreza, para tener algo, mejorar en condiciones económicas, el sueño de tener una casita, en fin, hacer algo más, principalmente por los hijos. Antes el café era lo que nos daba dinero; o sea, cosechábamos café y al año sabíamos que teníamos dinero para el sustento de la familia, para comprar algo, pero entró el ejército a nuestro pueblo y eso se terminó, o sea se echaron a perder todos esos trabajos, ahora para conseguir dinero pues no tenemos un empleo, no hay empleo en la región, por eso muchos decidieron migrar dentro del país y otros decidimos ya venirnos para acá (a Estados Unidos), como digo, para tener algo de económico para poder mantener a la familia (California, 2005).

El problema es que en un contexto donde todos viven bajo las mismas condiciones económicas y en el que se aspira a la igualdad, no es fácil convencer a quienes se oponen a la migración de que ésta es la única alternativa que hay para ganarse la vida en la región. De ahí que la imagen de la migración como «necesidad» haya sido contestada con la imagen de la migración como «ambición». Para algunas bases rebeldes la salida de sus compañeros no está provocada por una 
situación de pobreza, sino por el deseo de «tener dinero» y acceder a un nuevo estilo de vida propio de la ciudad. Esta disputa de sentidos ha abierto al interior de las comunidades una discusión en torno a lo que significa tener «necesidad»y el tipo de vida al que se aspira.

Por ejemplo, aunque en la región todos coinciden en que se encuentran en una situación económica precaria, como ellos mismos dicen: «por algo nos levantamos en armas». Mientras los militantes zapatistas siguen pensando que la lucha y la organización colectiva son la mejor vía para cambiar sus condiciones de vida y "salir adelante», los migrantes consideran que la lucha no ha tenido los efectos esperados y que en el actual contexto regional, la mejor opción para ganarse la vida es la migración a Estados Unidos, donde en unos cuantos días de trabajo los migrantes pueden llegar a ganar lo que en su región ganarían en un mes.

En resumen, zapatistas y migrantes aspiran por igual a tener una «vida mejor", pero existen divergencias sobre lo que esto significa. Para las bases zapatistas tener una buena vida es: «trabajar sin patrón», «tener suficientes tierras», "estar organizados», "estar unidos», "estar con la familia» y no tanto tener dinero u otro tipo de bienes asociados con la vida urbana. Para muchos jóvenes, en cambio, una buena vida es tener acceso a ciertos bienes de consumo que hasta ahora les eran prescindibles e inaccesibles, pero que poco a poco están siendo valorados e incorporados a la vida comunitaria mediante las remesas de la migración. En el fondo, este debate nos permite ver cómo la migración inevitablemente introduce al interior de las comunidades disputas simbólicas en torno al tipo de vida que se aspira, a lo que se considera imprescindible para vivir, al tipo de objetos y actividades que se valoran.

\section{LA MIGRACIÓN COMO ALIVIO O LIBERACIÓN}

Otro significado que se le da a la migración es de alivio o liberación, en tres diferentes sentidos, cada uno de ellos asociado con situaciones concretas de la vida cotidiana. En el primer caso, la migración es vista como una forma de liberarse de ciertas normas comunitarias, particularmente de la prohibición del consumo de bebidas alcohólicas. Podrá parecer absurdo pero posiblemente la ley zapatista que ha provocado mayor descontento entre algunas de sus bases - particularmente masculinas y jóvenes- es la que prohíbe la venta y el consumo de alcohol. Aunque todos coinciden en que el alcohol ha jugado un papel muy negativo al interior de sus comunidades - por eso elaboraron esa ley-, hay jóvenes a quienes les molesta esta prohibición e imaginan el Norte como un espacio lleno de libertad para la fiesta y la diversión.

En el segundo caso la migración se asocia con la «libertad de movimiento» y la posibilidad de conocer lugares en los que nunca han estado. Hay que recordar que hasta el 2001, había numerosos retenes militares en toda la cañada que impe- 
dían el libre tránsito y sometían a la población a revisiones e interrogatorios permanentes, por lo que para guardar su seguridad cada comunidad controlaba las salidas de sus bases y quien quería desplazarse tenía que pedir permiso.

Finalmente, la migración también se vive como «liberación» en el sentido de "descarga»; es decir, como la posibilidad de desembarazarse de ciertas obligaciones o responsabilidades vinculadas con los cargos y trabajos asignados por la comunidad o el movimiento. El ejercicio de la autonomía en las comunidades zapatistas exige un alto nivel de participación ciudadana. Todas las bases zapatistas tienen algún cargo o algún tipo de responsabilidad; y se les demanda una activa participación en los eventos, las reuniones y las asambleas del movimiento. Aunque se trata de una minoría, para algunos jóvenes esta demanda permanente de participación en la vida colectiva resulta a veces pesada y puede convertirse en una motivación para emigrar.

Para la generación de militantes que inició el movimiento es difícil entender que sus hijos u otros jóvenes vean en la migración una «liberación». Para esta generación ser libre significa, sobre todo, "tener suficiente tierra para cultivar» y no tener que trabajar bajo las órdenes de un patrón. Don José (60 años), integrante de las bases zapatistas de María Trinidad que lleva más de 15 años de participación activa en el movimiento, comenta pensativamente: «iCómo es la vida!... nosotros luchamos para no tener patrón y nuestros hijos se van al Norte a buscarlo y hasta pagan para ir» (Chiapas, 2006).

\section{LA MIGRACIÓN COMO RECOMPOSICIÓN PERSONAL}

Otro sentido que los migrantes dan a su migración es lo que he llamado «recomposición personal», es decir, la posibilidad de re-hacer su vida. Pese a los nuevos espacios de participación política que el zapatismo les ha abierto a las mujeres (véase Hernández, 2008), su reconocimiento al interior de las comunidades todavía está muy asociado con su capacidad para ser esposas y madres; es decir, son valoradas en la medida en que forman una familia. Las mujeres que no lo hacen tienen que vivir en una suerte de «minoría de edad» al abrigo del padre o algún hermano. ${ }^{5}$ De ahí que para las madres solteras o separadas la migración se vea como una oportunidad para reconstruir su vida afectiva y personal. Aunque existen excepciones, para las madres solteras o separadas, las expectativas a futuro son perma-

\footnotetext{
${ }^{5}$ En las comunidades de toda la región la mayor parte de los hombres solteros prefieren casarse con mujeres muy jóvenes y vírgenes. Las madres solteras o las mujeres que «fracasaron» en su matrimonio son estigmatizadas socialmente, consideradas como de «segunda categoría», por lo que sus opciones matrimoniales se restringen. Las prácticas opresivas hacia la mujer no deben verse como una particularidad de los «usos y costumbres» indígenas, ni como un «rasgo» inherente a sus culturas. La violencia contra la mujer es una práctica generalizada en casi todas las sociedades industrializadas y democráticas, así como en aquellas en vías de desarrollo ya que todas son sociedades patriarcales.
} 
necer en la casa paterna o casarse con algún hombre viudo (y seguramente con muchos hijos que mantener). Para muchas jóvenes ninguna de estas opciones resulta atractiva, ellas aspiran a rehacer su vida y volver a formar sus familias. Para estas mujeres, la migración les abre la posibilidad de volver a encontrar una pareja a la altura de sus expectativas y una vez convertidas en enviadoras de remesas les permite además afirmarse positivamente y obtener nuevas formas de reconocimiento al interior de sus pueblos.

Algunos jóvenes de María Trinidad que decidieron dejar el movimiento, también vieron en la migración una vía para la recomposición personal ya que la mayoría experimentaron su salida como un proceso doloroso y pasaron por un periodo de crisis personal, no sólo porque las salidas se realizaron en medio de un conflicto que dividió y creó enormes tensiones al interior de las comunidades, sino también porque implicó la pérdida de una pertenencia que les era central para definirse y posicionarse en la región, una pertenencia que durante años afirmaron positivamente y que funcionó como fuente de estima personal. Para casi todos los hombres en esta situación, la migración es la oportunidad perfecta para recuperar la estima perdida.

\section{LA MIGRACIÓN COMO MODA}

Conforme a lo largo y ancho de la selva se sucedieron las salidas hacia Estados Unidos, se constituyó una red migratoria sólida, un repertorio de acción y un imaginario social positivo sobre el otro lado de la frontera, la migración terminó por convertirse en una moda, es decir, «una cultura de la migración donde las personas migrarían porque todo mundo lo hace» (Castles, 2006: 42). Como un joven me dijo cuando platicábamos en el valle de California, medio en broma, medio en verdad: «El zapatismo ya pasó de moda, ahora yo sigo otra moda que es la migración».

Como explica Simmel (1923), la moda siempre está atravesada por una lógica de imitación y otra de distinción, ésta última permite satisfacer al mismo tiempo el deseo de afiliación y comunidad, así como el deseo de diferenciación y aislamiento; es decir, la moda realiza la síntesis entre la necesidad de aceptación, adhesión y seguridad y la necesidad de singularidad, distinción e individualismo (Simmel, 1923). Desde esta perspectiva, la migración sería un intento de las bases rebeldes - particularmente de la generación de zapatistas de cuna-, por resolver la tensión permanente entre el individuo y la comunidad. Mediante ella éstos buscan superar la tensión que emerge entre, por un lado, el deseo de todo joven de distinguirse del grupo, de marcar su diferencia, de «sobresalir» y el deseo o necesidad de formar parte de un grupo, de ser reconocido como parte de un colectivo.

La tensión entre una lógica de imitación -como deseo de pertenencia- y de una lógica de distinción -como deseo de diferenciación- se encuentra muy presente en la vida comunitaria. En las comunidades de la selva hay una búsqueda 
permanente del igualitarismo, que entra en tensión con el deseo de algunos de diferenciación, esto hace que cualquier moda o cambio se impongan con gran facilidad. En el siguiente testimonio, de una base zapatista de la región, queda expuesta de manera lúcida la tensión entre la búsqueda del igualitarismos y la diferencia:

Lo que nosotros vemos es que en las comunidades existe eso que llaman «igualitarismo». Todos queremos tener lo mismo, entonces si a un señor se le ocurre que va a pintar su casa, otros lo van a ver y van a decir "yo también quiero pintar mi casa» y va haber algunos que aunque no tengan dinero van a querer pintar su casa porque todos queremos estar igual. Pero yo debo analizar, pensar que la pintura está de más, es puro lujo, ya no es necesidad, es moda. Así pasa con lo del Norte, uno se va, el otro ve que regresa con algunas cositas y también va a querer irse para tener lo mismo, pero es igual, ya es lujo no necesidad (Emiliano, Chiapas, 2005).

Efectivamente, en las comunidades de la selva se aspira al igualitarismo y cualquier cambio o innovación que alguien introduzca con el fin de distinguirse -se trate de su indumentaria, de objetos domésticos, de estilo de vivienda, forma de trabajo o cualquier signo evidente de una diferenciación-, inmediatamente será percibida por el resto de la comunidad y al mismo tiempo que se volverá motivo de «crítica», será objeto de imitación, lo que provocará que se difunda rápidamente en la comunidad hasta que deje de ser un signo de distinción. Así ha pasado con la migración y hoy en día muchos adolescentes sueñan con irse al Norte siguiendo a sus hermanos mayores o amigos, nadie quiere quedarse atrás, todos quieren como ellos dicen: «probar» la experiencia y pasar a formar parte de los «norteños».

La «distinción» que se afirma con la migración se da tanto con respecto a la comunidad, como con las generaciones precedentes. No sólo tiene que ver con el acceso a un nuevo tipo de objetos o bienes personales, se relaciona sobre todo con en el tipo de experiencia vivida; es decir, con el hecho mismo de conocer otras tierras, otros trabajos, otras personas que nadie en el contexto comunitario conoce -salvo los que también emigraron-. Cuando regresan a sus pueblos, la distinción se expresa a través de nuevos comportamientos, vestimenta, forma de hablar, forma de bailar; los norteños tienen un estilo propio. Sin embargo, como sucede con todas las modas, la «distinción» que aporta la migración es pasajera, dura el tiempo que sus signos materiales permanecen, es decir, cuando la ropa nueva se gasta, los zapatos se rompen, los aparatos eléctricos se descomponen y los dólares que traen se acaban. Después de eso, el único signo de distinción será la experiencia vivida. Como explica un miembro de la Junta de Buen Gobierno; cuando le pregunto por el cambio que sufren los que se van al Norte, me dice:

El cambio es temporal, llegan con gorra, sombrerazo, bota norteña y a los seis meses eso se gasta y tienen que comprar lo mismo que nosotros y ya estamos otra vez ves- 
tidos igual, con lo que hay de por sí en la región. Llegan creídos, gordos, quieren matar pollo todos los días, pero al rato que se acaba su dinero ya están comiendo otra vez su frijol y su pozol todos los días, igual que nosotros. Así pasa, lo que viene del Norte se acaba ligero, se descompone y al rato ya estamos iguales todos otra vez. Entonces ¿̇e qué sirvió que se fueran? (Chiapas, 2006).

\title{
LA MIGRACIÓN COMO AVENTURA
}

Para muchos jóvenes la migración representa una «aventura» personal y colectiva. Es decir, una experiencia de naturaleza arriesgada, compuesta por eventos y encuentros inesperados, que sale de lo cotidiano y que implica un alto grado de incertidumbre (véase Simmel, 2002). Un evento que nunca se puede planear, ni medir completamente, porque supone lanzarse a lo desconocido, sin saber cuál será el resultado final, pero que les permite escapar de lo que Majakovskji llamó «la banalidad de lo cotidiano» (en Mezzadra, 2005: 44). El siguiente testimonio, de un migrante de 60 años de una comunidad no-zapatista de la región, expresa esta búsqueda:

\begin{abstract}
Yo no me voy al Norte por necesidad. No es por presumirle pero en mi pueblo tengo casa de material, tengo una tienda, tengo cafetales, tierra, no me falta nada. Mis hijos ya están grandes, ya les di todo lo que pude. También ellos me dicen que para qué me voy, pero pues yo les digo que hay que ir a conocer otras caras, oír otras voces, andar un poco. Quiero ir a aprender otros trabajitos. Es como los ricos que tienen dinero para irse de vacaciones, ellos pueden conocer otros países porque tienen dinero, tienen papeles; nosotros aunque tengamos el dinero, no nos dan los papeles, entonces pues la única forma para conocer un poquito pues es con la emigración (Roberto, Chiapas, 2005).
\end{abstract}

Las primeras salidas al Norte se hacen bajo grandes dosis de incertidumbre propias de la migración. Sin embargo, los jóvenes migrantes siempre tiene confianza en su viaje y en su suerte. Como dice Simmel (2002: 79), el aventurero se fía de su propia fuerza, cree en su buena estrella, aunque el carácter incierto de su viaje le imprima a su aventura una cierta dosis de fatalismo. El migrante se abandona a estos dos sentimientos -confianza y fatalismo-; de ahí que la aventura migratoria se realice entre la pasividad y la actividad, entre eso que nosotros conquistamos y lo que nos es dado (Simmel, 2002: 76). Durante el viaje, el migrante al mismo tiempo que está en la lógica de actuar y emprender, se entrega a su suerte o destino, ya que gran parte de esta aventura escapa a su control.

Cuando la migración se vive como aventura, la imagen del migrante se inviste de una fuerte dimensión épica opuesta a la de «desertor». El migrante aparece como una suerte de héroe cuyo viaje se transforma en una odisea, en la que abundan tanto las aventuras adversas como las favorables, y frente a las cuales el 
protagonista tiene que salir adelante. Esta imagen heroica se construye, en gran medida, durante el retorno a los pueblos de origen, cuando los recién llegados narran sus hazañas del otro lado de la frontera.

\section{LA APERTURA COMUNITARIA ANTE LA MIGRACIÓN}

La salida de Eugenio y la de un grupo de ocho jóvenes que emigraron en el año 2003 abrieron definitivamente el camino hacia Estados Unidos para los habitantes de María Trinidad. A partir de ese momento, las migraciones al Norte no han parado, cada salida produce migrantes potenciales ya que fortalece la red migratoria regional, alimenta los repertorios de acción migratoria, así como los imaginarios sociales que estimulan la salida de nuevos jóvenes.

Así, en un lapso menor a cinco años, la migración se ha convertido para muchos jóvenes en una nueva alternativa de vida. Hoy, todos son migrantes potenciales, de ahí que la mayor parte de las familias zapatistas de María Trinidad terminarán por enfrentarse a los dilemas que emergen cuando un hijo, un hermano, un esposo o cualquier otro familiar cercano decide partir. Como explica una base zapatista:

En cada familia siempre hay un hijo que es rebelde y que de por sí no va obedecer, entonces aunque les hablemos, aunque les digamos que se queden, ellos se van a ir. Se les habla, se les explica pero si su deseo es irse pues ya no hay nada que hacer. Cuando se les mete la idea a los jóvenes, pues ya no hay cómo. Pero nosotros aquí seguimos resistiendo (Rómulo, Chiapas, 2005).

Dada la situación, todas las familias tuvieron que flexibilizar su posición y aceptar la partida inminente de sus hijos porque no había forma de detenerlos. La comunidad se da cuenta que no tiene la fuerza para parar el fenómeno, así que replantea su posición original: en vez de prohibir la migración de sus bases, la acepta pero intenta regularla. Sabe que si no lo hace, otros militantes abandonarán también el movimiento.

Actualmente, en todas las comunidades zapatistas los militantes tienen derecho a emigrar hacia Estados Unidos a condición de que lo hagan con la autorización de la comunidad y cumplan con los acuerdos al respecto. La asamblea es el espacio donde se negocian las salidas y se construyen los acuerdos sobre sus términos. Por lo general, en los acuerdos se establece el tiempo que el futuro migrante podrá ausentarse y se define el monto que tendrá que pagar por los trabajos comunitarios que dejará de aportar para su pueblo. El periodo aceptado para ausentarse de la comunidad va de uno a cinco años; por ejemplo, en María Trinidad se permiten cuatro años, pero en comunidades donde la migración es más reciente el permiso es sólo de uno.

El acuerdo no es inamovible, cuando la situación lo requiere los términos de las salidas se renegocian, ya que el fenómeno migratorio cambia rápidamente. Se 
trata de buscar las mejores soluciones ante situaciones inéditas para la comunidad. De acuerdo a lo que explica un miembro de la Junta de Buen Gobierno en entrevista (Chiapas, 2006), en un principio las comunidades de la zona fronteriza acordaron que no se fijaría ningún tiempo límite para ausentarse del pueblo, cada persona definiría de manera individual la duración de su migración. Entonces, los hombres comenzaron a ausentarse de cinco a seis años y ya no había quien se hiciera cargo de todas las tareas comunitarias. Esto obligó a replantear el acuerdo comunitario; actualmente el permiso es de dos años y posteriormente el migrante tiene la obligación de quedarse tres años en el pueblo cumpliendo con sus servicios. Hay que señalar que son los propios migrantes quienes vieron la necesidad de normar las salidas para que su pueblo pudiera seguir funcionando. Este tipo de convenios se parece mucho al que han hecho algunas comunidades oaxaqueñas en las que los altos índices de migración han puesto en peligro el sistema de organización comunitaria.

El monto que el migrante debe pagar va de dos mil a cuatro mil pesos por año. Ese dinero se destina a cubrir los trabajos comunitarios que el migrante no podrá realizar en su ausencia. El cobro de «cuotas» a los migrantes es una práctica generalizada en otras comunidades indígenas de México con altos índices de migración. Este mecanismo se ve como una especie de "pago de impuesto» por los servicios que la familia del migrante goza, y ha permitido que los migrantes conserven su «ciudadanía comunitaria».

La apertura de las bases rebeldes ante la migración no sólo se refleja en la construcción de los acuerdos comunitarios para regular las salidas, sino que también en sus percepciones. Poco a poco la migración dejó de ser equiparada a la rendición y al abandono del movimiento. Las posiciones frente al fenómeno se matizaron, dejaron de expresarse en blanco y negro. Las comunidades zapatistas le han abierto un espacio a la migración. Hoy, casi todas las familias zapatistas de María Trinidad tienen, al menos, un familiar trabajando en Estados Unidos. La migración ya no es vista exclusivamente como el fin de la militancia o como una fuente latente de conflictos que anuncia el fin de las solidaridades comunitarias. La migración es aceptada como una nueva estrategia para ganarse la vida y para los migrantes es, además, una forma de rehacer su vida.

\section{CONCLUSIÓN}

A partir de la reconstrucción del inicio de la migración en María Trinidad, una comunidad zapatista de la Selva Lacandona, he tratado de mostrar en estas páginas cómo el fenómeno migratorio nació en medio de grandes tensiones comunitarias y de un conflicto del que emergen múltiples subjetividades, algunas de las cuales le disputan al movimiento su hegemonía como el mejor proyecto para resolver las demandas de los pueblos, e incluso como el proyecto de vida más deseable. 
Las primeras migraciones en María Trinidad tuvieron lugar en el periodo 2002-2003, en una coyuntura nacional nada esperanzadora pues todas las instancias del gobierno se habían negado a cumplir con los Acuerdos de San Andrés. Además, para este momento la guerra de baja intensidad había comenzado a cobrar las primeras bajas zapatistas en María Trinidad, por lo que las salidas al Norte coincidieron con las primeras salidas del movimiento.

Lo que intenté mostrar en el artículo fue que la migración provocó un conflicto comunitario en el que se opusieron dos tipos de subjetividades y en el que los actores se disputaron la definición del sentido del fenómeno migratorio y la forma de gestionarlo. Por un lado, aquellas bases zapatistas que definieron la migración como una rendición, un abandono y un peligro para la comunidad y el movimiento. Por otro, las que lo definieron públicamente como una forma legítima de obtener recursos económicos y le dieron también el sentido de una liberación, una aventura, una moda y una forma de recomposición personal. Este conflicto en torno a los sentidos de la acción migratoria expresa dos proyectos que coexisten al interior de las comunidades rebeldes: el proyecto de las autonomías zapatistas fundado en la organización colectiva por el bien común, cuya aspiración es la transformación profunda de la sociedad, y el proyecto de la migración a Estados Unidos, fundado en la acción individual o familiar para la satisfacción de necesidades y aspiraciones personales muy concretas.

Aunque en un principio estos dos proyectos parecían irreconciliables -ya que mientras el primero necesita de la presencia y participación activa de sus bases, el segundo provoca su ausencia por periodos prolongados- hoy coexisten en tensión y en permanente negociación ambos proyectos. Las comunidades zapatistas poco a poco le han abierto un espacio a la migración y han pasado de una etapa de rechazo total del fenómeno, a una etapa de apertura en la que se dieron cuenta de que la migración no tiene por qué implicar el abandono del movimiento, ni de las responsabilidades frente a la comunidad. De hecho, diversas experiencias en otras regiones del país muestran cómo el vínculo y el compromiso de los migrantes con sus pueblos de origen se mantiene a lo largo de los años de migración (Fox y Rivera Salgado, 2004). Hoy al interior de los pueblos rebeldes se están reinventando nuevas formas de compromiso militante, nuevas relaciones sociales, nuevas «maneras de vivir juntos» (Touraine, 1997) que permitan una conexión entre las aspiraciones colectivas del movimiento y las aspiraciones personales de los jóvenes migrantes.

\section{BIBLIOGRAFÍA}

Aauino, Alejandra y Korinta Maldonado (1998), La lucha por la tierra en una comunidad de la selva Lacandona, tesis de licenciatura en etnología, Escuela Nacional de Antropología e Historia, México. 
CAStles, Stephen (2006), «Factores que hacen y deshacen las políticas migratorias», en Alejandro Portes y Josh Dewin (coords.), Repensando las migraciones. Nuevas perspectivas teóricas y Empíricas, México, Miguel Ángel Porrúa/Universidad Autónoma de Zacatecas, pp.33-66.

Durand, Jorge y Douglas Massey (2003), Clandestinos. Migración México-Estados Unidos en los albores del siglo XXI, México, Miguel Ángel Porrúa/Universidad Autónoma de Zacatecas.

Fox, Jonathan y Gaspar Rivera-Salgado, (2004), «Introducción», en Jonathan Fox y Gaspar Rivera-Salgado (coords.), Indígenas mexicanos migrantes en los Estados Unidos, México, Universidad de California Sta. Cruz/Universidad de Zacatecas/Miguel Ángel Porrúa pp. 9-74.

Hernández, R. Aída, Paz Sarela y María Teresa Sierra Sierra (eds.) (2004), El Estado y los indígenas en tiempos del PAN: Neoindigenismo, legalidad e identidad, México, CIESAS.

(coord.) (2008), Etnografías e historias de resistencia: mujeres indígenas, procesos organizativos y nuevas identidades políticas, México, CIESAS.

Jauregui, Alfredo y María de Jesús Ávila (2007), «Estados Unidos, lugar de destino para los migrantes chiapanecos», Migraciones Internacionales, vol. 4, núm. 1, pp. 5-38.

Melucci, Alberto (1999), Acción colectiva, vida cotidiana y democracia, México, Colegio de México.

Mezzadra, Sandro (2005), Derecho de fuga. Migraciones ciudadanía y globalización, Madrid, Traficantes de Sueños.

Mutersbaugh, Tad (2002), «Migration, common property, and communal labor: cultural politics and agency in a Mexican village», Political Geography, núm. 21, pp. 473-494.

Pickard, Miguel (2006), «La migración vista desde Chiapas», Chiapas al Día, núm. 519, 16/09/06, Chiapas: Centro de Investigación Económica y Política de Acción Comunitaria (CIEPAC). Disponible en: http://www.ciepac.org/boletines/chiapasaldia.php? $\mathrm{id}=519$

Simmel, George (2002), La Philosophie de l'aventure, París, L'Arche. (1923), «Filosofía de la moda», Revista de Occidente, vol. 1, núm. 1, pp. 44-47.

Touraine, Alain (1997), Pourrons-nous vivre ensemble? Égaux et différents, París, Fayard. Villafuerte, Daniel y María del Carmen García (2006), "Crisis rural y migraciones en Chiapas», Migración y Desarrollo, núm. 6, primer semestre, pp. 102-130.

(2008), Migraciones en el sur de México y Centroamérica, México, Unicach/Miguel Ángel Porrúa, pp. 343-382. 